\title{
Contribuições da educação física na prevenção e tratamento da obesidade infantil
}

A obesidade é considerada pela medicina como uma doença complexa e multifatorial que tem como principal característica o acúmulo exacerbado de tecido adiposo em todo o corpo. Está associada a fatores metabólicos, fisiológicos, alimentares, comportamentais e também sociais. Direta ou indiretamente é responsável pela ampliação considerável da incidência de mortalidade na população. Essa doença se constitui como um grave problema de saúde pública que precisa ser combatido. Acomete todas as faixas etárias e classes sociais. E tem atingido alto índice nas crianças. Nesse sentido, este estudo tem como objetivo geral analisar na literatura as contribuições da Educação Física para prevenção e tratamento da obesidade. Trata-se de uma revisão integrativa da literatura com base em dados eletrônicos Scielo e Lilacs, nos estudos publicados durante os anos de 2013 e 2018. Foi possível concluir que as contribuições da Educação Física para prevenção e tratamento da obesidade com atividades com foco na cultura corporal por possibilitar práticas lúdicas estimulam processos sistemáticos de exercícios físicos que contribuem para a conscientização de uma alimentação saudável; incentiva mudanças de estilos de vida ativa; fomenta a conscientização sobre malefícios da obesidade, sobrepeso e comorbidades; incentiva a inserção da família no processo de prevenção e tratamento da obesidade.

Palavras-chave: Educação Física; Obesidade; Educação; Saúde; Práticas corporais.

\section{Contributions of physical education in the prevention and treatment of childhood obesity}

Obesity is considered by medicine as a complex and multifactorial disease whose main characteristic is the exacerbated accumulation of adipose tissue throughout the body. It is associated with metabolic, physiological, dietary, behavioral and also social factors. Directly or indirectly it is responsible for the considerable increase in the incidence of mortality in the population. This disease is a serious public health problem that needs to be tackled. It affects all age groups and social classes. And it has reached a high rate in children. In this sense, this study has the general objective of analyzing in the literature the contributions of Physical Education for the prevention and treatment of obesity. This is an integrative literature review based on electronic data Scielo and Lilacs, in the studies published during the years 2013 and 2018. It was possible to conclude that the contributions of Physical Education for the prevention and treatment of obesity with activities focused on culture body for making playful practices stimulate systematic processes of physical exercises that contribute to the awareness of healthy eating; encourages changes in active lifestyles; promotes awareness of the harmful effects of obesity, overweight and comorbidities; encourages the insertion of the family in the obesity prevention and treatment process.

Keywords: Physical Education; Obesity; Education; Cheers; Physical exercises.

Topic: Educação Física

Reviewed anonymously in the process of blind peer.
Received: 19/10/2020

Approved: 20/01/2021

Tarciana Cecília de Souza Ferreira (it)

Universidade do Sul de Santa Catarina, Brasil

http://lattes.cnpq.br/6041849208221003

http://orcid.org/0000-0001-9759-6952

tarciana.ferreira@prof.educ.rec.br

Tereza Luiza de França (iD)

Universidade Federal de Pernambuco, Brasil

http://lattes.cnpq.br/8809406318062867

http://orcid.org/0000-0003-4168-2258

tereza.franca@ufpe.br

Referencing this:

FERREIRA, T. C. S.; FRANÇA, T. L.. Contribuições da educação física na prevenção e tratamento da obesidade infantil. Scire Salutis, v.11, n.1, p.7-23, 2021. DOI: http://doi.org/10.6008/CBPC22369600.2021 .001 .0002 


\section{INTRODUÇÃO}

Atuais estudos indicam que a obesidade se situa como patologia complexa, multifatorial, com fatores de riscos de natureza endógenos e exógenos. Isso implica no uso de estratégias de prevenção e tratamento nas quais sejam considerados os fatores específicos de cada caso.

Segundo Teixeira et al. (2016) a obesidade é uma doença crônico-degenerativa com uma principal característica - o acúmulo exacerbado de tecido adiposo em todo o corpo. Outra característica relevante é sua associação a fatores metabólicos, fisiológicos, e sociais, atribuindo-lhe ser de origem multifatorial.

Definida, também, como uma doença crônica que causa excessivos consumos de energia devido necessidades calóricas do indivíduo. O que vem a causar a multiplicação de quantidades elevadas de tecido adiposo.

Segundo Ribeiro et al. (2016) a obesidade é um fator de risco para diversas comorbidades, tais como: diabetes mellitus do tipo 2, hipertensão arterial sistêmica, dislipidemias, doenças cardiovasculares. Cabe também destacar que o tecido adiposo tem importante função endócrina, que servem para secretar citocinas, denominadas como sendo adipocitas.

Os fatores inerentes ao metabolismo, em alguns casos, são determinantes para o acúmulo de gordura. Ou seja, existem possibilidades de pessoas que mesmo com hábitos sedentários não ficam acima do peso, enquanto outras, mesmo com uma alimentação equilibrada vivem com oscilações de peso.

De acordo com o Instituto Brasileiro de Geografia e Estatística - IBGE (citado por BRAVIN et al., 2015), cerca de $16,7 \%$ dos adolescentes brasileiros estão acima do peso, com maior prevalência nas regiões Nordeste e Sul, que possuem respectivamente $11,7 \%$ e 19,8\%. E o excesso de peso entre crianças também vem aumentando significativamente. O que implica, que nos últimos trinta anos, a obesidade se expandiu em todas as regiões do Brasil, mesmo considerando a diversidade de faixa etária, gênero, e extrato de renda.

A literatura aponta indícios sobre a etiologia multifatorial que envolve fatores de ordem social, ambiental e sócio -cultural, uma vez que os problemas de peso estão diretamente associados aos hábitos alimentares e ao estilo de vida.

Apesar das consequências por excesso de peso serem múltiplas, resultando desde o aumento da pressão arterial, passando pela mudança do perfil lipídico e glicídio, problemas nas articulações, na lombar e de pressão arterial.

Segundo Pimenta et al. (2014), devido os problemas com o tratamento de saúde, de estética, da baixa estima, as pessoas consideradas obesas têm altos gastos financeiros. Destacando que, no âmbito da saúde pública, está patologia tem implicado no aumento do percentual de internações, devido seus inúmeros malefícios.

Neste contexto, se compreende a necessidade de buscar concretas e efetivas estratégias para a prevenção, o controle e o tratamento da obesidade, o que contribui para diminuição significativa dos índices de aumento desta patologia. A qual, para estes autores, é considerada como um grave problema de saúde pública. 
Durante a infância seu tratamento torna-se bem mais difícil o entendimento acerca dos danos que podem resultar. Geralmente as crianças acompanham os hábitos dos pais e familiares, bem como colegas, dificultando as mudanças de hábitos. Que, por vezes determinam padrões corporais na vida adulta.

Segundo Ferreira et al. (2017) a criança com excesso de massa corpórea tem maior possibilidade de desenvolver diversas doenças. O distúrbio de peso corpóreo, em muitos casos resulta de doenças genéticas, alterações nutricionais e/ou de elementos endócrino-metabólicos. Estes casos, do tipo exógena poderá resultar pela ingestão de calorias acima da necessidade diária, inclusive pelo consumo de gorduras saturadas, excesso de lipídios e/ou pela falta de atividades corporais no cotidiano.

As consequências por excesso de peso são múltiplas, resultando desde o aumento da pressão arterial, passando pela mudança do perfil lipídico e glicídio, deixando a criança bastante suscetível a doenças.

Segundo Manfre et al. (2016) "as atividades corporais são essenciais ao combate à obesidade contribuindo no processo de equilíbrio energético, na redução dos riscos de doenças associadas, a esta doença".

Estudiosos afirmam que as atividades corporais realizadas, também, na disciplina de Educação Física são relevantes para o crescimento e desenvolvimento das crianças na medida em que, ao vivenciar o jogo, a dança, o esporte, a luta, a ginástica, criam hábitos de práticas regulares da cultura corporal, favorecendo para o processo de conscientização sobre a importância destas práticas para saúde em geral e, especificamente para prevenção da obesidade.

A Educação Física na escola ao ser sistematizada com base nas concepções de práticas corporais, em que se valoriza o corpo em todas suas dimensões, tem seu foco no sentido e significado na melhoria do estilo de vida, o que colabora efetivamente para superar as posturas infantis que, cada vez mais, são nutridas por atividades sedentárias provocadas, por exemplo, pela televisão, celular, tablet, computador para jogos, vídeo games, dentre outras atividades que, conjuntamente com uma dieta inadequada, contribuem para o desenvolvimento corporal, atingindo o sobrepeso.

Nestas perspectivas, surge a problemática: De que forma a educação física tem contribuído na prevenção e tratamento da obesidade? Esta pesquisa se justifica, pela relevância de analisarmos e socializarmos estratégias de combate à obesidade infantil com a sistematização de práticas corporais baseadas em novas abordagens pedagógicas. E, também, por considerarmos que está temática situa-se atualidade. Com a socialização deste estudo, pretendemos contribuir para o debate e, com base na literatura, ser possível apontar e/ou contribuir com estudos e pesquisas sobre as contribuições para prevenção e tratamento da obesidade advindas das práticas corporais vividas pela Educação Física no universo escolar.

\section{REVISÃO TEÓRICA}

\section{Caracterização da obesidade}

A obesidade pode genericamente ser concebida a partir da quantidade de gordura, e isto implica em excesso de gordura no tronco, aumento do nível de colesterol sérico, sendo um fator de risco para 
doenças cardiovasculares e desenvolvimento de diabetes. Apesar de durante a infância ser associada aos fatores genéticos, são comprovados em vários casos relacionados aos hábitos de sedentarismo e maior consumo de gorduras e açúcares.

Segundo Bravin et al. (2015) o processo etiológico multifatorial é determinado, também, pelos polimorfismos nos mais variados genes, bem como disfunções hormonais, hipotalâmicas que estão vinculadas à saciedade, apetite, fome, balanço energético positivo, bem ao aumento do processo de liberação de adipocinas pró-inflamatórias. Cabe destacar, aqui, a ingestão calórica total que ultrapassa o índice suficiente ao dia-dia do ser humano.

A vida sedentária caracterizada pela falta de horário fixo para as refeições, excesso de comida, número de refeições diárias, dieta calórica com o uso demasiado de produtos industrializados, tempo diante do computador, da TV. É fundamental avaliar o quanto esses conjuntos de elementos influenciam a rotina das crianças. Ou seja, torna-se necessário incluir nestes hábitos estratégias de superação para ser possível prevenir e/ou tratar a obesidade. É fundamental compreendermos que as taxas metabólicas podem ser modificadas, ainda que de maneira parcial, uma vez que o metabolismo pode ser acelerado por intermédio da reeducação alimentar associada às práticas corporais cotidianas.

Outrossim, dialogando com a fundamentação teórica deste estudo, convém lembrar que a sociedade atual incentiva às a crianças, práticas alimentares excessivas regadas de fast-food, refrigerantes, guloseimas. É importante salientar, que a pesquisa não se trata da proibição destes alimentos inadequados. Pois, com a proibição, se encadeia a ansiedade pela busca dos mesmos. O que se alerta é que o excesso e o hábito de ingerir dietas sustentadas por alto teor calórico, muitas vezes, acima das necessidades vitais, provocando problemas advindos deste excesso.

Afora as consequências para saúde, a obesidade também tem implicações para as crianças em termos de inquietação com a estética corporal, tendo em vista a difusão dos padrões de beleza estética definidos pela sociedade, pela família, presente na escola e nas redes de interação social da criança. O que a deixam vulneráveis à problemas psicossociais, relativos à autoestima, em relação à aceitação, bem como o processo de interação à aceitação, a autoestima, e seu processo de interação com ambiente e os outros.

\section{Educação Física e Possíveis Contribuições na Prevenção e Tratamento da Obesidade}

Segundo Alves Júnior et al. (2016) o corpo humano torna-se para o desenvolvimento de movimentos, incluindo atividades em níveis mais progressivos. Todavia, as práticas corporais precisam fazer parte do estilo de vida, de modo que o organismo humano possa continuar a se desenvolver.

Nessa perspectiva, cabe destacar que a Educação Física é uma disciplina que visa desenvolver no educando de forma estruturada o hábito de práticas corporais a fim de melhorar ou manter um ou mais componentes, levando em consideração os benefícios proporcionados à saúde.

Segundo Souza et al. (2016) ocorre que o corpo humano precisa movimentar-se, sendo estimulado a fim de manter sua capacidade de rendimento e, no caso da criança, o crescimento, bem como o melhor desempenho possível das suas capacidades motoras. 
A Educação Física na escola deve promover práticas corporais, uma vez que serve como estratégia para combater a obesidade, e também as comorbidades associadas a esta doença. Isso posto, é fundamental para saúde de crianças acima do peso, e juntamente com hábitos saudáveis, sono regular, boa alimentação pode servir como estratégia no tratamento da obesidade. Nesse sentido, as modificações que as práticas corporais promovem favorecendo a perda de massa corporal total, resultando na criança a redução da obesidade abdominal.

Segundo Paixão et al. (2016) a forma como as crianças identificam a Educação Física é essencial para o devido controle da obesidade, bem como, para formação de um estilo de vida saudável, e isto implica também na necessidade de inserção da família para que a criança tenha uma alimentação saudável.

Nesse contexto, cabe destacar que a aula de Educação Física pode ser planejada, com objetivos estabelecidos, bem como acerca da disseminação do conhecimento e da importância da atividade física para a saúde. Assim, o professor de educação Física amplia as possibilidades de conhecimento a medida em que programa as atividades, levando em conta os objetivos a serem alcançados, e as peculiaridades de cada aluno, cuidando também em atuar na prevenção e tratamento da obesidade e sobrepeso.

Segundo Rica et al. (2014) as aulas de Educação Física é uma atividade muito almejada pelas crianças, pois a concebem como um espaço para brincadeira, diversão e interação social. Sendo assim, a educação física precisa ser direcionada para despertar nas crianças o interesse pelas atividades físicas.

Nesse sentido, o professor de Educação Física ao atuar no desenvolvimento de atividades esportivas e recreativas na escola, também ajudam na redução da perda de peso corporal, pois a atividade física é essencial para saúde.

Segundo Dias et al. (2017) os movimentos corporais atuam de maneira positiva a fim de evitar comorbidades relacionadas à obesidade, tais como problemas respiratórios, problemas cardiovasculares, tendo em vista, por exemplo, que movimentos corporais resistidos atuam no ganho e manutenção de massa muscular, bem como na melhoria cardiorrespiratória, pois ajudam no fortalecimento do coração e também dos pulmões. Além disto, movimentos aeróbicos atuam diretamente na perda de gordura corporal.

Todavia, cabe destacar que a prática de Educação Física não deve se restringir apenas na escola. 0 aluno deve ser incentivado a praticar exercícios entre três ou quatro vezes por semana, uma vez que se exercitar apenas duas vezes por semana não reduz a gordura corporal e o peso.

Segundo a Organização Mundial de Saúde OMS (citada por LOURENÇO et al., 2017) recomenda-se que a prática de educação física ocorra de acordo com a faixa etária das crianças, tendo em vista as especificidades de cada um, a intensidade, e os tipos de exercícios a serem realizados.

A prática regular da Educação Física implica em uma transformação do indivíduo acerca de todas suas vivências diárias. Ao passo que a atividade física vai se transformando numa prática de vida do indivíduo, outras transformações dentro da rotina diária vão se evidenciando. O indivíduo passa vivenciar processos que operam em sinergia com a promoção em saúde e impactam positivamente em sua qualidade de vida.

Nesse sentido, constitui-se como a parte mais variável do lado por gasto energético, o que representa entre $5 \%$ a $40 \%$ do gasto calórico diário. Assim, quando se combina práticas corporais com 
restrição calórica, é possível reduzir o sobrepeso, uma vez que o movimento corporal ajuda no catabolismo de gorduras, bem como no processo de aceleração do tecido adiposo.

Segundo Almeida et al. (2016) a atividade física na escola pode ser orientada para despertar tanto o hábito de praticar atividade física, quanto também demonstrar suas contribuições na saúde e na qualidade de vida, centrando atividade nas práticas que combatem à obesidade, e promovam a interação social.

Para tanto, cabe destacar que a sociedade incentiva determinados padrões de beleza, que desde a tenra idade as crianças adquirem esta percepção. Assim, a criança com sobrepeso ou obesa tem dificuldades e interação, podendo também vivenciar situações constrangedores no próprio ambiente escolar.

Nesse sentido, segundo Santos et al., (2016) os benefícios psicológicos para os obesos com as práticas corporais dizem respeito à melhoria de sensação de bem-estar, humor, autoestima, contribuindo também para redução da ansiedade, tensão, depressão, tendo em vista a melhoria do processo de interação social, e a qualidade de vida.

A Educação Física é um elemento na estratégia global, tendo em vista as contribuições relativas à formação do hábito de atividade física, as contribuições que se referem à saúde, minimização de riscos de comorbidade associadas à obesidade, levando em consideração as especificidades envolvidas neste processo.

\section{METODOLOGIA}

Para um estudo ser considerado integrativo é possível verificar algumas etapas, as quais são: Identificação do problema, apresentado na Introdução; Busca na literatura; Avaliação dos dados; Análise e apresentação dos resultados relevantes; Discussão à luz da literatura, com base nos critérios de análise.

Considerando o problema apresentado na introdução, o passo seguinte é a busca na literatura. A busca foi realizada no mês de julho de 2018. Para o refinamento da pesquisa, foi definida uma amostra, obedecendo aos seguintes critérios de inclusão: Periódicos indexados na Scielo e LILACS; Artigos descritos pelos descritores DeCS/MeSH: Educação Física; Obesidade; Exercícios Físicos; Artigos publicados em língua portuguesa; Artigos com textos completos disponíveis; Publicação no período de 2013 a 2018, uma vez que permitem a discussão a partir de estudos publicados recentemente, dando maior atualidade aos achados encontrados na literatura.

E, teve como critérios de exclusão: Artigos com textos não disponíveis; Artigos em língua estrangeira; Estudos de casos; Artigos publicados fora do período estabelecido para as publicações.

As buscas para o LILACS e o Scielo foram realizadas através da plataforma de buscas da Biblioteca Virtual em Saúde (BVS/BIREME). Foi procurado em cada artigo ano de publicação, o objetivo, e as conclusões que contribuem para resolução da problemática em pesquisa. Os dados são apresentados em tabelas e quadros.

\section{RESULTADOS E DISCUSSÃO}

Nesta pesquisa inicialmente foram encontradas 53 publicações, dentre as quais: 23 provenientes 
do LILACS; 30 provenientes do Scielo.

Após a análise dos critérios de inclusão da amostra da literatura, a pesquisa ficou com 25 publicações, sendo: 8 provenientes do LILACS; 17 provenientes do Scielo.

A estratificação acerca dos anos de publicação, é possível verificar que o ano com maior número de publicações é o ano de 2016, como pode ser visto na Tabela 1.

Tabela 1: Ano de publicação dos estudos da amostra.

\begin{tabular}{llc}
\hline Ano de publicação & $\mathbf{N}$ & \% \\
\hline 2013 & 2 & $8 \%$ \\
2014 & 4 & $16 \%$ \\
2015 & 3 & $12 \%$ \\
2016 & 7 & $28 \%$ \\
2017 & 6 & $24 \%$ \\
2018 & 3 & $12 \%$ \\
Total & $\mathbf{2 5}$ & $\mathbf{1 0 0 \%}$ \\
\hline
\end{tabular}

De acordo com os dados do quadro 1, é possível perceber que a maioria dos estudos são convergentes entre as suas conclusões, tendo em vista as especificidades da Educação Física, a obesidade, e a importância do exercício físico para a saúde da criança. Assim, cabe destacar o papel da escola neste contexto, e do profissional de Educação Física na promoção do hábito de exercícios físicos regular.

Quadro 1: Demonstrativo dos artigos que integram a Revisão Integrativa.

\begin{tabular}{|c|c|c|c|c|}
\hline Data & Título & Autores & Objetivo & Conclusões \\
\hline 2016 & $\begin{array}{l}\text { Efeito das práticas } \\
\text { extensionistas de } \\
\text { reeducação } \\
\text { alimentar e } \\
\text { atividade física no } \\
\text { peso corporal de } \\
\text { crianças. }\end{array}$ & $\begin{array}{l}\text { ALMEIDA, M. E. F.; } \\
\text { RAMOS, J. A. S. C.; } \\
\text { GALVÃO, B. F. R. C.; } \\
\text { SILVA, A. H.; MOREIRA, } \\
\text { M. M.; TAVARES, R. O.; } \\
\text { SANTOS, V. S. }\end{array}$ & $\begin{array}{l}\text { Avaliar como as } \\
\text { práticas de reeducação } \\
\text { alimentar e atividade } \\
\text { física interferia no peso } \\
\text { corporal de crianças } \\
\text { com sobrepeso e } \\
\text { obesidade. }\end{array}$ & $\begin{array}{l}\text { As práticas de reeducação alimentar e } \\
\text { atividade física influenciam } \\
\text { positivamente o peso corporal de } \\
\text { crianças com sobrepeso e obesidade, } \\
\text { cabendo destacar que apenas a atividade } \\
\text { física isoladamente não influencia de } \\
\text { maneira significativa. }\end{array}$ \\
\hline 2016 & $\begin{array}{l}\text { Auto-percepção do } \\
\text { papel do } \\
\text { profissional de } \\
\text { educação física no } \\
\text { combate à } \\
\text { obesidade: um } \\
\text { estudo piloto. }\end{array}$ & $\begin{array}{l}\text { ALVES JUNIOR, T. A.; } \\
\text { FERNANDES JUNIOR, J. } \\
\text { A.; SILVA, C. S.; SOUSA, } \\
\text { L. A.; CARVALHO, A. B. } \\
\text { L.; ANTONIO, B.; } \\
\text { FIGUEREDO, S.; IVNA, } \\
\text { Z.; PONTES JÚNIOR, J. }\end{array}$ & $\begin{array}{l}\text { Compreender a } \\
\text { percepção do } \\
\text { profissional de } \\
\text { Educação Física quanto } \\
\text { ao seu papel na } \\
\text { dinâmica do combate à } \\
\text { obesidade. }\end{array}$ & $\begin{array}{l}\text { O profissional de Educação Física possui } \\
\text { uma percepção relevante do seu papel } \\
\text { no combate à obesidade visto que suas } \\
\text { ações permitem a realização de práticas } \\
\text { assistenciais que promovam a prevenção } \\
\text { e a baixa incidência dessa enfermidade. }\end{array}$ \\
\hline 2018 & $\begin{array}{l}\text { Relação entre } \\
\text { atividade física, } \\
\text { aptidão física e } \\
\text { risco } \\
\text { cardiovascular: } \\
\text { estudo em } \\
\text { Muzambinho, } \\
\text { Minas Gerais. }\end{array}$ & $\begin{array}{l}\text { BARBOSA, J. P. A. S.; } \\
\text { BASSO, L.; } \\
\text { BARTHOLOMEU, T.; } \\
\text { PRISTA, A.; REZENDE, J. } \\
\text { A. S.; OLIVEIRA, J. A.; } \\
\text { TANI, G. O.; MAIA, J. A. } \\
\text { R.; FORJAZ, C. L. M. }\end{array}$ & $\begin{array}{l}\text { Investigar a relação } \\
\text { entre atividade física, } \\
\text { aptidão física e risco } \\
\text { cardiovascular. }\end{array}$ & $\begin{array}{l}\text { A relação inversa entre atividade física, } \\
\text { aptidão física e risco cardiovascular } \\
\text { limitou-se aos indicadores de aptidão } \\
\text { física e aos de obesidade, sugerindo que } \\
\text { em populações com alta taxa de } \\
\text { indivíduos fisicamente ativos pode ajudar } \\
\text { a reduzir a obesidade. }\end{array}$ \\
\hline 2015 & $\begin{array}{l}\text { A influência do } \\
\text { exercício físico na } \\
\text { obesidade infantil. }\end{array}$ & $\begin{array}{l}\text { BRAVIN, M. B.; ROSA, A. } \\
\text { R.; PARREIRA, M. B.; } \\
\text { PRADO, A. F. }\end{array}$ & $\begin{array}{l}\text { Investigar a eficácia da } \\
\text { prescrição de atividade } \\
\text { física para crianças com } \\
\text { sobrepeso e obesidade, } \\
\text { de acordo com } \\
\text { produção científica } \\
\text { publicada. }\end{array}$ & $\begin{array}{l}\text { Com base nos achados, ficou clara a } \\
\text { necessidade de se realizar estudos que } \\
\text { favoreçam as evidências dos efeitos de } \\
\text { tratamento baseado em exercícios físicos } \\
\text { globais associados a controle de } \\
\text { dislipidemias em crianças obesas. }\end{array}$ \\
\hline 2018 & $\begin{array}{l}\text { Diabetes Mellitus } \\
\text { tipo } 3 \text { e exercício } \\
\text { físico: relações } \\
\text { entre obesidade, } \\
\text { resistência } \\
\text { insulínica e } \\
\text { distúrbios } \\
\end{array}$ & $\begin{array}{l}\text { CERRONE, A. L.; } \\
\text { TEIXEIRA, C. V. L. S.; } \\
\text { REBELO, R. A.; } \\
\text { CARANTI, D. A.; } \\
\text { GOMES, R. J. }\end{array}$ & $\begin{array}{l}\text { Descrever o papel do } \\
\text { exercício físico como } \\
\text { tratamento não } \\
\text { farmacológico para o } \\
\text { diabetes mellitus tipo } 3 .\end{array}$ & $\begin{array}{l}\text { A prática regular de exercícios físicos se } \\
\text { mostrou uma estratégia promissora em } \\
\text { termos de prevenção e tratamento para } \\
\text { o diabetes mellitus tipo } 3 \text {. }\end{array}$ \\
\hline
\end{tabular}




\begin{tabular}{|c|c|c|c|c|}
\hline & cognitivos. & & & \\
\hline 2017 & $\begin{array}{l}\text { Obesidade e } \\
\text { políticas públicas: } \\
\text { concepções e } \\
\text { estratégias } \\
\text { adotadas pelo } \\
\text { governo brasileiro. }\end{array}$ & $\begin{array}{l}\text { DIAS, P. C.; HENRIQUES, } \\
\text { P.; ANJOS, L. A.; } \\
\text { BURLANDY, L. }\end{array}$ & $\begin{array}{l}\text { Analisar como a } \\
\text { obesidade vem sendo } \\
\text { abordada em políticas } \\
\text { do SUS e do SISAN, } \\
\text { incluindo conceitos, } \\
\text { indicadores, estratégias } \\
\text { de ação e de } \\
\text { articulação } \\
\text { institucional, } \\
\text { relacionadas com } \\
\text { alimentação e nutrição. }\end{array}$ & $\begin{array}{l}\text { As propostas do SUS apontam para uma } \\
\text { abordagem integrada e intrassetorial da } \\
\text { obesidade, e as do SISAN reforçam a } \\
\text { intersetorialidade em uma perspectiva } \\
\text { ampliada que desafia as estruturas } \\
\text { institucionais setoriais vigentes. }\end{array}$ \\
\hline 2014 & $\begin{array}{l}\text { Exercícios físicos } \\
\text { como estratégia de } \\
\text { prevenção e } \\
\text { tratamento da } \\
\text { obesidade: } \\
\text { aspectos } \\
\text { fisiológicos e } \\
\text { metodológicos. }\end{array}$ & $\begin{array}{l}\text { DIAS, I. B. F.; } \\
\text { MONTENEGRO, R. A.; } \\
\text { MONTEIRO, W. D. }\end{array}$ & $\begin{array}{l}\text { Revisar o papel dos } \\
\text { exercícios aeróbios e } \\
\text { resistidos na obesidade, } \\
\text { bem como detalhar as } \\
\text { diretrizes utilizadas nas } \\
\text { sessões de treinamento } \\
\text { físico direcionadas a } \\
\text { indivíduos obesos. }\end{array}$ & $\begin{array}{l}\text { O exercício físico tem sido destacado } \\
\text { como importante elemento na } \\
\text { abordagem não farmacológica para o } \\
\text { tratamento e prevenção da obesidade. } \\
\text { Diversos estudos têm demonstrado que } \\
\text { a prática sistemática do exercício atua } \\
\text { positivamente na redução do peso } \\
\text { corporal e nos fatores de risco } \\
\text { associados. }\end{array}$ \\
\hline 2014 & $\begin{array}{l}\text { Prevenção da } \\
\text { obesidade de forma } \\
\text { multidisciplinar no } \\
\text { contexto escolar. }\end{array}$ & $\begin{array}{l}\text { ESMERALDO, R. S.; } \\
\text { SILVA, A. O.; LIMA, F. } \\
\text { D.; SILVA, V. V.; } \\
\text { DANTAS, R. A. E.; } \\
\text { OLIVEIRA, R. J.; SOUZA, } \\
\text { H. A.; MOTA, M. R. }\end{array}$ & $\begin{array}{l}\text { Descrever métodos que } \\
\text { possam contribuir para } \\
\text { a prevenção da } \\
\text { obesidade nas escolas, } \\
\text { por meio da educação } \\
\text { física escolar. }\end{array}$ & $\begin{array}{l}\text { Na prevenção desta doença, ensaios de } \\
\text { base familiar, de longa duração, com } \\
\text { treinos combinados e intervenções na } \\
\text { dieta e nos exercícios mostraram } \\
\text { resultados positivos. }\end{array}$ \\
\hline 2017 & $\begin{array}{l}\text { Contribuição da } \\
\text { atividade física na } \\
\text { prevenção da } \\
\text { obesidade em } \\
\text { alunos do } 4^{\circ} \text { ao } 5^{\circ} \\
\text { ano. }\end{array}$ & $\begin{array}{l}\text { FERREIRA, J. B.; } \\
\text { CARVALHO, M. S.; } \\
\text { SOUZA, F. T. R. }\end{array}$ & $\begin{array}{l}\text { Descrever as } \\
\text { dificuldades das } \\
\text { crianças com obesidade } \\
\text { na pratica da atividade } \\
\text { física. }\end{array}$ & $\begin{array}{l}\text { Concluiu-se que a obesidade tem como } \\
\text { aliado a ausência da realização da } \\
\text { atividade física. E, as dificuldades dizem } \\
\text { respeito ao desconforto no } \\
\text { desenvolvimento dos exercícios, dor, e } \\
\text { falta de motivação. }\end{array}$ \\
\hline 2013 & $\begin{array}{l}\text { Exercício físico e } \\
\text { obesidade mórbida: } \\
\text { uma revisão } \\
\text { sistemática. }\end{array}$ & $\begin{array}{l}\text { FONSECA JÚNIOR, S. J.; } \\
\text { SÁ, C. G. A. B.; } \\
\text { RODRIGUES, P. A. F.; } \\
\text { OLIVEIRA, A. J.; } \\
\text { FERNANDES FILHO, J. }\end{array}$ & $\begin{array}{l}\text { Investigar os efeitos de } \\
\text { programas de } \\
\text { exercícios físicos no } \\
\text { tratamento clínico e } \\
\text { cirúrgico da obesidade } \\
\text { mórbida. }\end{array}$ & $\begin{array}{l}\text { Programas de exercícios físicos aeróbicos } \\
\text { e resistidos mostraram ser importantes } \\
\text { componentes no tratamento da } \\
\text { obesidade mórbida. Cuidados especiais } \\
\text { no momento da determinação do } \\
\text { volume-intensidade de exercícios físicos } \\
\text { são necessários para a aderência ao } \\
\text { tratamento. }\end{array}$ \\
\hline 2017 & $\begin{array}{l}\text { Itinerário } \\
\text { terapêutico de } \\
\text { pacientes com } \\
\text { obesidade } \\
\text { atendidos em } \\
\text { serviço de alta } \\
\text { complexidade de } \\
\text { um hospital } \\
\text { universitário. } \\
\end{array}$ & $\begin{array}{l}\text { YOUNES, S.; FRIZON, M. } \\
\text { L. R.; LUCIA, M.; } \\
\text { ARAÚJO, F.; CEZAR, A. }\end{array}$ & $\begin{array}{l}\text { Analisar o itinerário } \\
\text { terapêutico de } \\
\text { pacientes com } \\
\text { obesidade. }\end{array}$ & $\begin{array}{l}\text { Poucos pacientes aderiram a } \\
\text { tratamentos alternativos. A intervenção } \\
\text { e orientação de profissionais da saúde, } \\
\text { característica mostrou-se decisiva na } \\
\text { procura por tratamento especializado } \\
\text { para a obesidade. }\end{array}$ \\
\hline 2017 & $\begin{array}{l}\text { Atividade física } \\
\text { como uma } \\
\text { estratégia } \\
\text { terapêutica em } \\
\text { saúde mental: } \\
\text { revisão integrativa } \\
\text { com implicação } \\
\text { para o cuidado de } \\
\text { enfermagem. } \\
\end{array}$ & $\begin{array}{l}\text { LOURENÇO, B. S.; } \\
\text { PERES, M. A. A.; PORTO, } \\
\text { I. S.; OLIVEIRA, R. M. P.; } \\
\text { DUTRA, V. F. D. }\end{array}$ & $\begin{array}{l}\text { Descrever as evidências } \\
\text { científicas acerca do } \\
\text { efeito da prática regular } \\
\text { de atividade física por } \\
\text { pessoas em saúde } \\
\text { mental. }\end{array}$ & $\begin{array}{l}\text { Concluiu-se a eficácia terapêutica da } \\
\text { atividade física, acrescentando benefícios } \\
\text { individuais e coletivos que proporcionam } \\
\text { a socialização e a promoção de bem- } \\
\text { estar. }\end{array}$ \\
\hline 2016 & $\begin{array}{l}\text { A influência da } \\
\text { educação física no } \\
\text { combate à } \\
\text { obesidade infantil. }\end{array}$ & $\begin{array}{l}\text { MANFRE, S. D. M.; } \\
\text { SELOW, M. L. C. }\end{array}$ & $\begin{array}{l}\text { Analisar a influência da } \\
\text { disciplina de Educação } \\
\text { Física e da atuação do } \\
\text { professor dessa área no } \\
\text { combate à obesidade } \\
\text { infantil. }\end{array}$ & $\begin{array}{l}\text { As aulas de Educação Física devem ser } \\
\text { planejadas visando } \\
\text { despertar o interesse das crianças a } \\
\text { praticar exercícios físicos regularmente } \\
\text { para promover melhorias na saúde com } \\
\text { controle em relação ao peso corporal. }\end{array}$ \\
\hline 2017 & $\begin{array}{l}\text { Excesso de peso, } \\
\text { obesidade, passos e }\end{array}$ & $\begin{array}{l}\text { OLIVEIRA, L. C.; } \\
\text { FERRARI, G. L. M.; }\end{array}$ & $\begin{array}{l}\text { Identificar a quantidade } \\
\text { de passos/dia }\end{array}$ & $\begin{array}{l}\text { Nos meninos, passos/dia e atividade } \\
\text { física de moderada a vigorosa foram }\end{array}$ \\
\hline
\end{tabular}




\begin{tabular}{|c|c|c|c|c|}
\hline & $\begin{array}{l}\text { atividade física de } \\
\text { moderada a } \\
\text { vigorosa em } \\
\text { crianças. }\end{array}$ & $\begin{array}{l}\text { ARAÚJO, T. L.; } \\
\text { MATSUDO, V. }\end{array}$ & $\begin{array}{l}\text { necessários para atingir } \\
\text { a recomendação de } \\
\text { atividade física de } \\
\text { moderada a vigorosa } \\
\text { em crianças. }\end{array}$ & $\begin{array}{l}\text { negativamente associados com o índice } \\
\text { de massa corporal, independentemente } \\
\text { da raça, renda familiar, escolaridade dos } \\
\text { pais, tempo de tela, padrão de dieta e } \\
\text { tempo sedentário. }\end{array}$ \\
\hline 2015 & $\begin{array}{l}\text { Efeitos metabólicos } \\
\text { do exercício físico } \\
\text { na obesidade } \\
\text { infantil: uma visão } \\
\text { atual. }\end{array}$ & $\begin{array}{l}\text { PAES, S. T.; MARINS, J. } \\
\text { C. B.; ANDREAZZI, A. E. }\end{array}$ & $\begin{array}{l}\text { Descrever sobre os } \\
\text { efeitos do exercício } \\
\text { físico sobre diferentes } \\
\text { variáveis metabólicas } \\
\text { da obesidade infantil. }\end{array}$ & $\begin{array}{l}\text { O exercício físico, independentemente } \\
\text { do tipo, mostra-se capaz de promover } \\
\text { adaptações positivas sobre a obesidade } \\
\text { infantil, principalmente por atuar na } \\
\text { restauração da homeostase celular e } \\
\text { sistema cardiovascular. }\end{array}$ \\
\hline 2016 & $\begin{array}{l}\text { Percepção da } \\
\text { obesidade juvenil } \\
\text { entre professores } \\
\text { de educação física } \\
\text { na educação básica. }\end{array}$ & $\begin{array}{l}\text { PAIXÃO, J. A.; AGUIAR, } \\
\text { C. M.; SILVEIRA, F. S. A. }\end{array}$ & $\begin{array}{l}\text { Analisar as percepções } \\
\text { de professores de } \\
\text { Educação Física em } \\
\text { escolas de educação } \\
\text { básica com relação à } \\
\text { obesidade e o papel da } \\
\text { escola e da Educação } \\
\text { Física como formas de } \\
\text { controle. }\end{array}$ & $\begin{array}{l}\text { A insuficiência da carga horária semanal } \\
\text { de aulas de Educação Física para lidar } \\
\text { com o tema da obesidade de forma } \\
\text { sistemática, bem como suas implicações, } \\
\text { é consenso entre esses professores. }\end{array}$ \\
\hline 2018 & $\begin{array}{l}\text { Percepção de } \\
\text { Estudantes Sobre } \\
\text { Saúde, Alimentação } \\
\text { e Atividade Física } \\
\text { Após Intervenção } \\
\text { com a Metodologia } \\
\text { da } \\
\text { Problematização. } \\
\end{array}$ & $\begin{array}{l}\text { PERES, C. V.; LARA, S.; } \\
\text { COPETTI, J.; LANES, K. } \\
\text { G.; SOARES, M. C. }\end{array}$ & $\begin{array}{l}\text { Descrever a percepção } \\
\text { dos estudantes acerca } \\
\text { da saúde, alimentação } \\
\text { e atividade física. }\end{array}$ & $\begin{array}{l}\text { Assim, foi possível constatar que houve } \\
\text { mudança de percepção nos dois grupos } \\
\text { de estudantes após a intervenção. Com } \\
\text { isso, evidencia-se que é mais eficiente } \\
\text { para promover conhecimento sobre as } \\
\text { temáticas em saúde do que as aulas } \\
\text { expositivas. }\end{array}$ \\
\hline 2014 & $\begin{array}{l}\text { As contribuições da } \\
\text { intervenção } \\
\text { multiprofissional na } \\
\text { obesidade infantil } \\
\text { no contexto de } \\
\text { violência urbana. }\end{array}$ & $\begin{array}{l}\text { PIMENTA, T. A. M.; } \\
\text { PEREIRA, I. M. D. }\end{array}$ & $\begin{array}{l}\text { Discutir os fatores } \\
\text { ambientais da } \\
\text { obesidade infantil, } \\
\text { analisar o processo de } \\
\text { estigmatização social da } \\
\text { obesidade. }\end{array}$ & $\begin{array}{l}\text { As crianças obesas há um demasiado } \\
\text { consumo de produtos industrializados, } \\
\text { horas em frente à televisão e o } \\
\text { videogame, ritmo de vida acelerado, } \\
\text { poucas políticas públicas e privadas de } \\
\text { estímulo à atividade física. }\end{array}$ \\
\hline 2016 & $\begin{array}{l}\text { A obesidade na } \\
\text { infância e o } \\
\text { protagonismo da } \\
\text { educação física } \\
\text { escolar. }\end{array}$ & $\begin{array}{l}\text { RIBEIRO, L. S.; TRIANI, F. } \\
\text { S. }\end{array}$ & $\begin{array}{l}\text { Apresentar um ponto } \\
\text { de vista sobre o } \\
\text { protagonismo da } \\
\text { Educação Física Escolar } \\
\text { no combate a } \\
\text { obesidade. }\end{array}$ & $\begin{array}{l}\text { Embora as aulas de educação física não } \\
\text { sejam suficientes em termos do combate } \\
\text { direto à obesidade, seu protagonismo se } \\
\text { apresenta em termos conceituais e } \\
\text { atitudinais, na medida em que cria } \\
\text { espaço dentro das aulas para debater a } \\
\text { temática da obesidade e motivar os } \\
\text { hábitos de atividade física. }\end{array}$ \\
\hline 2013 & $\begin{array}{l}\text { Prevalência de } \\
\text { sobrepeso e } \\
\text { obesidade em } \\
\text { escolares com idade } \\
\text { de } 7 \text { a } 17 \text { anos, } \\
\text { residentes nos } \\
\text { municípios } \\
\text { pertencentes à } \\
\text { secretaria de } \\
\text { desenvolvimento } \\
\text { regional de São } \\
\text { Miguel do } \\
\text { Oeste/SC. }\end{array}$ & $\begin{array}{l}\text { RIBEIRO, A. J. P.; } \\
\text { FACHINETO, S.; } \\
\text { PEDROZO, S. C.; } \\
\text { TRENTIN, A. P.; } \\
\text { ZAPOANI, C. }\end{array}$ & $\begin{array}{l}\text { Verificar prevalência de } \\
\text { sobrepeso e obesidade } \\
\text { em escolares de } \\
7 \text { a } 17 \text { anos. }\end{array}$ & $\begin{array}{l}\text { Dessa forma, conclui-se que em ambos } \\
\text { os gêneros, a prevalência de sobrepeso e } \\
\text { obesidade em escolares de } 7 \text { a } 17 \text { anos é } \\
\text { considerada alta, pois atinge uma fração } \\
\text { de } 24,8 \% \text { da população feminina e } 26,4 \% \\
\text { da masculina. }\end{array}$ \\
\hline 2014 & $\begin{array}{l}\text { Contribuições da } \\
\text { atividade física no } \\
\text { tratamento de } \\
\text { idosos com } \\
\text { transtorno } \\
\text { depressivo: uma } \\
\text { breve revisão. } \\
\end{array}$ & $\begin{array}{l}\text { RICA, R. L.; MIRANDA, } \\
\text { M. L. J.; EVANGELISTA, } \\
\text { A. L.; POLITO, L. F. T.; } \\
\text { SERRA, A. J.; FIGUEIRA } \\
\text { JUNIOR, A.; GAMA, E. } \\
\text { F.; ALONSO, A. C.; } \\
\text { BOCALINI, D. S. } \\
\end{array}$ & $\begin{array}{l}\text { Verificar os efeitos da } \\
\text { atividade física em } \\
\text { portadores de } \\
\text { transtornos } \\
\text { depressivos. }\end{array}$ & $\begin{array}{l}\text { A atividade física colabora para } \\
\text { socialização, oferece benefícios corporais } \\
\text { e fisiológicos, e tendem a ter uma } \\
\text { redução significativa nos níveis de } \\
\text { depressão. }\end{array}$ \\
\hline 2017 & $\begin{array}{l}\text { Benefícios da } \\
\text { atividade física no } \\
\text { controle da } \\
\text { obesidade infantil. }\end{array}$ & $\begin{array}{l}\text { SILVA, F. A. L.; BEZERRA, } \\
\text { J. A. X. }\end{array}$ & $\begin{array}{l}\text { Avaliar os benefícios da } \\
\text { atividade física no } \\
\text { controle da obesidade } \\
\text { infantil. }\end{array}$ & $\begin{array}{l}\text { Os benefícios da atividade física no } \\
\text { controle da obesidade infantil são: } \\
\text { prevenção de alterações } \\
\text { metabólicas, prevenção de doenças } \\
\text { crônicas cardiovasculares, }\end{array}$ \\
\hline
\end{tabular}




\begin{tabular}{|c|c|c|c|c|}
\hline & & & & $\begin{array}{l}\text { melhoramento na qualidade do sono, } \\
\text { controle de estresse e bem-estar com a } \\
\text { estética corporal. }\end{array}$ \\
\hline 2016 & $\begin{array}{l}\text { Exercícios físicos } \\
\text { como ferramenta } \\
\text { de enfrentamento } \\
\text { às comorbidades } \\
\text { associadas à } \\
\text { obesidade: revisão } \\
\text { de literatura. }\end{array}$ & $\begin{array}{l}\text { SOUZA, G. E. S.; } \\
\text { PRUDENCIATTO, M. R.; } \\
\text { TANAKA, R. S.; } \\
\text { MARTELLI, A.; DELBIM, } \\
\text { L. R. }\end{array}$ & $\begin{array}{l}\text { Abordar os aspectos } \\
\text { epidemiológicos do } \\
\text { sobrepeso e da } \\
\text { obesidade em como } \\
\text { importante fator de } \\
\text { agravo. }\end{array}$ & $\begin{array}{l}\text { Os benefícios da prática de exercícios são } \\
\text { consensuais, na melhoria no } \\
\text { condicionamento cardiovascular, } \\
\text { controle do diabetes mellitus, no aspecto } \\
\text { psicológico e social, contribuindo para a } \\
\text { melhoria da qualidade de vida. }\end{array}$ \\
\hline 2016 & $\begin{array}{l}\text { Influências da mídia } \\
\text { e das relações } \\
\text { sociais na } \\
\text { obesidade de } \\
\text { escolares e a } \\
\text { educação física } \\
\text { como ferramenta } \\
\text { de prevenção. }\end{array}$ & $\begin{array}{l}\text { TEIXEIRA, R. C.; COSTA, } \\
\text { S. P.; OLIVEIRA, G. V.; } \\
\text { CANDIDO, F. N.; } \\
\text { RAFAEL, L. M.; MAZINI } \\
\text { FILHO, M. L. M. }\end{array}$ & $\begin{array}{l}\text { Verificar as influências } \\
\text { do estilo de vida, } \\
\text { relações sociais e da } \\
\text { mídia na obesidade } \\
\text { infantil e entender } \\
\text { como as aulas de } \\
\text { Educação Física podem } \\
\text { auxiliar na sua } \\
\text { prevenção. }\end{array}$ & $\begin{array}{l}\text { O professor de Educação Física não } \\
\text { consegue combater a obesidade, mas } \\
\text { consegue com uma importante } \\
\text { contribuição da mídia, conscientizar } \\
\text { esses alunos a respeito de hábitos } \\
\text { alimentares saudáveis e práticas } \\
\text { regulares de atividades físicas. }\end{array}$ \\
\hline 2015 & $\begin{array}{l}\text { Obesidade como } \\
\text { fator de risco para } \\
\text { morbidade e } \\
\text { mortalidade: } \\
\text { evidências sobre o } \\
\text { manejo com } \\
\text { medidas não } \\
\text { medicamentosas. }\end{array}$ & WANNMACHER, L. & $\begin{array}{l}\text { Verificar os principais } \\
\text { aspectos da obesidade, } \\
\text { bem como o risco para } \\
\text { morbidade e } \\
\text { mortalidade. }\end{array}$ & $\begin{array}{l}\text { Dentre os fatores ambientais que devem } \\
\text { ser corrigidos, destacam-se hábitos } \\
\text { alimentares incorretos e inatividade } \\
\text { física. Embora resultados satisfatórios } \\
\text { sejam difíceis de atingir, vale a pena } \\
\text { envidar esforços nesse sentido. }\end{array}$ \\
\hline
\end{tabular}

De acordo com os dados do quadro 2, foi verificado que a maioria dos estudos que compõem a amostra é de revisão de literatura, pois 60\% (15 artigos) é de revisão, e 40\% (10 artigos) pesquisa de campo. Isto aponta para necessidade de mais estudos com amostras constituídas de pesquisa de campo.

Quadro 2: Artigos inclusos para análise.

\begin{tabular}{|c|c|c|c|c|}
\hline Data & Título & Autores & Metodologia & Amostra \\
\hline 2016 & $\begin{array}{l}\text { Efeito das práticas extensionistas de } \\
\text { reeducação alimentar e atividade física } \\
\text { no peso corporal de crianças. }\end{array}$ & $\begin{array}{l}\text { ALMEIDA, M. E. F.; RAMOS, J. A. S. } \\
\text { C.; GALVÃO, B. F. R. C.; SILVA, A. } \\
\text { H.; MOREIRA, M. M.; TAVARES, R. } \\
\text { O.; SANTOS, V. S. }\end{array}$ & $\begin{array}{l}\text { Pesquisa de } \\
\text { campo }\end{array}$ & 350 crianças \\
\hline 2016 & $\begin{array}{l}\text { Auto-percepção do papel do profissional } \\
\text { de educação física no combate à } \\
\text { obesidade: um estudo piloto. }\end{array}$ & $\begin{array}{l}\text { ALVES JUNIOR, T. A.; FERNANDES } \\
\text { JUNIOR, J. A.; SILVA, C. S.; SOUSA, } \\
\text { L. A.; CARVALHO, A. B. L.; } \\
\text { ANTONIO, B.; FIGUEREDO, S.; } \\
\text { IVNA, Z.; PONTES JÚNIOR, J. }\end{array}$ & $\begin{array}{l}\text { Pesquisa de } \\
\text { campo }\end{array}$ & $\begin{array}{l}10 \text { profissionais } \\
\text { de educação } \\
\text { física }\end{array}$ \\
\hline 2018 & $\begin{array}{l}\text { Relação entre atividade física, aptidão } \\
\text { física e risco cardiovascular: estudo em } \\
\text { Muzambinho, Minas Gerais. }\end{array}$ & $\begin{array}{l}\text { BARBOSA, J. P. A. S.; BASSO, L.; } \\
\text { BARTHOLOMEU, T.; PRISTA, A.; } \\
\text { REZENDE, J. A. S.; OLIVEIRA, J. A.; } \\
\text { TANI, G. O.; MAIA, J. A. R.; FORJAZ, } \\
\text { C. L. M. }\end{array}$ & $\begin{array}{l}\text { Pesquisa de } \\
\text { campo }\end{array}$ & $\begin{array}{l}237 \\
\text { participantes }\end{array}$ \\
\hline 2015 & $\begin{array}{l}\text { A influência do exercício físico na } \\
\text { obesidade infantil. }\end{array}$ & $\begin{array}{l}\text { BRAVIN, M. B.; ROSA, A. R.; } \\
\text { PARREIRA, M. B.; PRADO, A. F. }\end{array}$ & $\begin{array}{l}\text { Revisão de } \\
\text { literatura }\end{array}$ & 13 artigos \\
\hline 2018 & $\begin{array}{l}\text { Diabetes Mellitus tipo } 3 \text { e exercício } \\
\text { físico: relações entre obesidade, } \\
\text { resistência insulínica e distúrbios } \\
\text { cognitivos. }\end{array}$ & $\begin{array}{l}\text { CERRONE, A. L.; TEIXEIRA, C. V. L. } \\
\text { S.; REBELO, R. A.; CARANTI, D. A.; } \\
\text { GOMES, R. J. }\end{array}$ & $\begin{array}{l}\text { Revisão de } \\
\text { literatura }\end{array}$ & 42 artigos \\
\hline 2017 & $\begin{array}{l}\text { Obesidade e políticas públicas: } \\
\text { concepções e estratégias adotadas pelo } \\
\text { governo brasileiro. }\end{array}$ & $\begin{array}{l}\text { DIAS, P. C.; HENRIQUES, P.; ANJOS, } \\
\text { L. A.; BURLANDY, L. }\end{array}$ & $\begin{array}{l}\text { Revisão de } \\
\text { literatura }\end{array}$ & 68 referências \\
\hline 2014 & $\begin{array}{l}\text { Exercícios físicos como estratégia de } \\
\text { prevenção e tratamento da obesidade: } \\
\text { aspectos fisiológicos e metodológicos. }\end{array}$ & $\begin{array}{l}\text { DIAS, I. B. F.; MONTENEGRO, R. A.; } \\
\text { MONTEIRO, W. D. }\end{array}$ & $\begin{array}{l}\text { Revisão de } \\
\text { literatura }\end{array}$ & 34 artigos \\
\hline 2014 & $\begin{array}{l}\text { Prevenção da obesidade de forma } \\
\text { multidisciplinar no contexto escolar. }\end{array}$ & $\begin{array}{l}\text { ESMERALDO, R. S.; SILVA, A. O.; } \\
\text { LIMA, F. D.; SILVA, V. V.; DANTAS, } \\
\text { R. A. E.; OLIVEIRA, R. J.; SOUZA, H. } \\
\text { A.; MOTA, M. }\end{array}$ & $\begin{array}{l}\text { Revisão de } \\
\text { literatura }\end{array}$ & 26 artigos \\
\hline
\end{tabular}




\begin{tabular}{|c|c|c|c|c|}
\hline 2017 & $\begin{array}{l}\text { Contribuição da atividade física na } \\
\text { prevenção da obesidade em alunos do } \\
4^{\circ} \text { ao } 5^{\circ} \text { ano. }\end{array}$ & $\begin{array}{l}\text { FERREIRA, J. B.; CARVALHO, M. S.; } \\
\text { SOUZA, F. T. R. }\end{array}$ & $\begin{array}{l}\text { Pesquisa de } \\
\text { campo }\end{array}$ & 21 alunos \\
\hline 2013 & $\begin{array}{l}\text { Exercício físico e obesidade mórbida: } \\
\text { uma revisão sistemática. }\end{array}$ & $\begin{array}{l}\text { FONSECA JÚNIOR, S. J.; SÁ, C. G. A. } \\
\text { B.; RODRIGUES, P. A. F.; OLIVEIRA, } \\
\text { A. J.; FERNANDES FILHO, J. }\end{array}$ & $\begin{array}{l}\text { Revisão de } \\
\text { literatura }\end{array}$ & 13 artigos \\
\hline 2017 & $\begin{array}{l}\text { Itinerário terapêutico de pacientes com } \\
\text { obesidade atendidos em serviço de alta } \\
\text { complexidade de um hospital } \\
\text { universitário. }\end{array}$ & $\begin{array}{l}\text { YOUNES, S.; FRIZON, M. L. R.; } \\
\text { LUCIA, M.; ARAÚJO, F.; CEZAR, A. }\end{array}$ & $\begin{array}{l}\text { Pesquisa de } \\
\text { campo }\end{array}$ & 21 pacientes \\
\hline 2017 & $\begin{array}{l}\text { Atividade física como uma estratégia } \\
\text { terapêutica em saúde mental: revisão } \\
\text { integrativa com implicação para o } \\
\text { cuidado de enfermagem. }\end{array}$ & $\begin{array}{l}\text { LOURENÇO, B. S.; PERES, M. A. A.; } \\
\text { PORTO, I. S.; OLIVEIRA, R. M. P.; } \\
\text { DUTRA, V. F. D. }\end{array}$ & $\begin{array}{l}\text { Revisão de } \\
\text { literatura }\end{array}$ & 8 artigos \\
\hline 2016 & $\begin{array}{l}\text { A influência da educação física no } \\
\text { combate à obesidade infantil. }\end{array}$ & MANFRE, S. D. M.; SELOW, M. L. C. & $\begin{array}{l}\text { Revisão de } \\
\text { literatura }\end{array}$ & 32 referências \\
\hline 2017 & $\begin{array}{l}\text { Excesso de peso, obesidade, passos e } \\
\text { atividade física de moderada a vigorosa } \\
\text { em crianças. }\end{array}$ & $\begin{array}{l}\text { OLIVEIRA, L. C.; FERRARI, G. L. M.; } \\
\text { ARAÚJO, T. L.; MATSUDO, V. }\end{array}$ & $\begin{array}{l}\text { Pesquisa de } \\
\text { campo }\end{array}$ & 1.557 crianças \\
\hline 2015 & $\begin{array}{l}\text { Efeitos metabólicos do exercício físico } \\
\text { na obesidade infantil: uma visão atual. }\end{array}$ & $\begin{array}{l}\text { PAES, S. T.; MARINS, J. C. B.; } \\
\text { ANDREAZZI, A. E. }\end{array}$ & $\begin{array}{l}\text { Revisão de } \\
\text { literatura }\end{array}$ & 39 artigos \\
\hline 2016 & $\begin{array}{l}\text { Percepção da obesidade juvenil entre } \\
\text { professores de educação física na } \\
\text { educação básica. }\end{array}$ & $\begin{array}{l}\text { PAIXÃO, J. A.; AGUIAR, C. M.; } \\
\text { SILVEIRA, F. S. A. }\end{array}$ & $\begin{array}{l}\text { Pesquisa de } \\
\text { campo }\end{array}$ & 15 professores \\
\hline 2018 & $\begin{array}{l}\text { Percepção de Estudantes Sobre Saúde, } \\
\text { Alimentação e Atividade Física Após } \\
\text { Intervenção com a Metodologia da } \\
\text { Problematização. }\end{array}$ & $\begin{array}{l}\text { PERES, C. V.; LARA, S.; COPETTI, J.; } \\
\text { LANES, K. G.; SOARES, M. C. }\end{array}$ & $\begin{array}{l}\text { Pesquisa de } \\
\text { campo }\end{array}$ & 24 estudantes \\
\hline 2014 & $\begin{array}{l}\text { As contribuições da intervenção } \\
\text { multiprofissional na obesidade infantil } \\
\text { no contexto de violência urbana. }\end{array}$ & $\begin{array}{l}\text { PIMENTA, T. A. M.; PEREIRA, I. M. } \\
\text { D. }\end{array}$ & $\begin{array}{l}\text { Pesquisa de } \\
\text { campo }\end{array}$ & 12 participantes \\
\hline 2016 & $\begin{array}{l}\text { A obesidade na infância e o } \\
\text { protagonismo da educação física } \\
\text { escolar. }\end{array}$ & RIBEIRO, L. S.; TRIANI, F. S. & $\begin{array}{l}\text { Revisão de } \\
\text { literatura }\end{array}$ & 47 artigos \\
\hline 2013 & $\begin{array}{l}\text { Prevalência de sobrepeso e obesidade } \\
\text { em escolares com idade de } 7 \text { a } 17 \text { anos, } \\
\text { residentes nos municípios pertencentes } \\
\text { à secretaria de desenvolvimento } \\
\text { regional de São Miguel do Oeste/SC. }\end{array}$ & $\begin{array}{l}\text { RIBEIRO, A. J. P.; FACHINETO, S.; } \\
\text { PEDROZO, S. C.; TRENTIN, A. P.; } \\
\text { ZAPOANI, C. }\end{array}$ & $\begin{array}{l}\text { Pesquisa de } \\
\text { campo }\end{array}$ & 1728 estudantes \\
\hline 2014 & $\begin{array}{l}\text { Contribuições da atividade física no } \\
\text { tratamento de idosos com transtorno } \\
\text { depressivo: uma breve revisão. }\end{array}$ & $\begin{array}{l}\text { RICA, R. L.; MIRANDA, M. L. J.; } \\
\text { EVANGELISTA, A. L.; POLITO, L. F. } \\
\text { T.; SERRA, A. J.; FIGUEIRA JUNIOR, } \\
\text { A.; GAMA, E. F.; ALONSO, A. C.; } \\
\text { BOCALINI, D. S. }\end{array}$ & $\begin{array}{l}\text { Revisão de } \\
\text { literatura }\end{array}$ & 33 artigos \\
\hline 2017 & $\begin{array}{l}\text { Benefícios da atividade física no controle } \\
\text { da obesidade infantil. }\end{array}$ & SILVA, F. A. L.; BEZERRA, J. A. X. & $\begin{array}{l}\text { Revisão de } \\
\text { literatura }\end{array}$ & 8 artigos \\
\hline 2016 & $\begin{array}{l}\text { Exercícios físicos como ferramenta de } \\
\text { enfrentamento às comorbidades } \\
\text { associadas à obesidade: revisão de } \\
\text { literatura. }\end{array}$ & $\begin{array}{l}\text { SOUZA, G. E. S.; PRUDENCIATTO, } \\
\text { M. R.; TANAKA, R. S.; MARTELLI, } \\
\text { A.; DELBIM, L. }\end{array}$ & $\begin{array}{l}\text { Revisão de } \\
\text { literatura }\end{array}$ & 43 artigos \\
\hline 2016 & $\begin{array}{l}\text { Influências da mídia e das relações } \\
\text { sociais na obesidade de escolares e a } \\
\text { educação física como ferramenta de } \\
\text { prevenção. }\end{array}$ & $\begin{array}{l}\text { TEIXEIRA, R. C.; COSTA, S. P.; } \\
\text { OLIVEIRA, G. V.; CANDIDO, F. N.; } \\
\text { RAFAEL, L. M.; MAZINI FILHO, M. } \\
\text { L. M. }\end{array}$ & $\begin{array}{l}\text { Revisão de } \\
\text { literatura }\end{array}$ & 51 artigos \\
\hline 2015 & $\begin{array}{l}\text { Obesidade como fator de risco para } \\
\text { morbidade e mortalidade: evidências } \\
\text { sobre o manejo com medidas não } \\
\text { medicamentosas. }\end{array}$ & WANNMACHER, L. & $\begin{array}{l}\text { Revisão de } \\
\text { literatura }\end{array}$ & 52 referências \\
\hline
\end{tabular}

Ao longo deste estudo foi possível identificar que os resultados obtidos pela Educação Física contribuem para o tratamento e prevenção da obesidade durante a infância, bem como no sentido de promover a formação de um estilo de vida com hábitos saudáveis e a práticas corporais.

Segundo Paixão et al. (2016) é essencial o processo de adequação da composição corporal ao 
percentual para faixa etária específica da criança, tendo em vista a prevenção contra obesidade e comorbidades relacionadas a esta doença.

Souza et al. (2016) concordam com a contribuição da Educação Física na melhoria da prevenção da obesidade e outras comorbidades. Este ponto é consensual em toda literatura a respeito desta temática. Os autores exemplificam que uma das principais causas das doenças cardiovasculares diz respeito ao acúmulo de placas de gorduras, o que impede a passagem do sangue e a irrigação correta dos tecidos. Assim, as práticas corporais contribuem para evitar os problemas cardiovasculares.

Cerrone et al. (2018) asseguram que a obesidade está ligada a várias etiologias, como a dislipidemia que necessita ser prevenida, pois se trata de alterações da concentração de lipídeos no sangue. Assim, a obesidade precisa ser prevenida deste a infância.

Acerca da ocorrência da obesidade durante a obesidade, Silva et al. (2017), destaca relatório da Comissão pelo fim da Obesidade Infantil publicado pela Organização Mundial da Saúde (OMS) existem cerca de 41 milhões de crianças menores de cinco anos são obesas ou têm sobrepeso, com prevalência maior em regiões de baixa e média renda.

Esse ponto também é consensual na literatura a respeito desta temática, como Fonseca Júnior et al. (2013) asseguram que a comercialização de alimentos que não são saudáveis, bem como bebidas não alcoólicas e contribuem para o sobrepeso e obesidade. Isso porque a má alimentação é um dos fatores que resultam na obesidade infantil.

Segundo Wannmacher (2015) a obesidade tem grande prevalência na infância, tendo em vista a má alimentação, o que aumenta a possibilidade de a criança adquirir sobrepeso, obesidade, e as doenças relacionadas, tendo em vista as especificidades envolvidas neste processo.

Ribeiro et al. (2013) afirmam que a obesidade na infância precisa ser combatida, tendo em vista que a obesidade em vários outros tipos de agravos na saúde está relacionada a esta doença, tornando a criança mais suscetível a desenvolver ao longo da vida a hipertensão arterial, diabetes mellitus, bem como doenças cardiovasculares.

Silva et al. (2017) concordam com a necessidade de prevenção e dos riscos da criança obesa e com sobrepeso, e asseguram que o professor de Educação Física tende a interagir não apenas durante a aplicação de movimentos corporais variados em suas aulas, mas também na detecção da obesidade, promovendo hábitos saudáveis, destacando os benefícios proporcionados pela atividade física, e do acompanhamento físico e nutricional realizado pela família.

Barbosa et al. (2018) asseguram que a Educação Física proporciona vários benefícios aos alunos, desde o momento em que incentivam o desenvolvimento das práticas corporais a fim de adquirir melhorias na saúde, e no próprio um estilo de vida saúde.

Ferreira et al. (2017) também concordam, tendo em vista, que, e acrescentam que as práticas corporais precisam ser apropriadas, levando em conta as especificidades de cada aluno, os objetivos a serem alcançados. A duração das práticas corporais deve ser de até 10 minutos, com a devida intensidade, frequência e sequência, sendo variada e atrativa, de modo que as crianças não sejam desestimuladas nem 
pensam em desistir de fazer a os movimentos corporais.

No que se refere aos tipos de práticas corporais que podem ser aplicadas nas aulas de Educação Física visando o melhor condicionamento físico dos alunos, Esmeraldo et al. (2014) asseguram que várias atividades podem ser aplicadas tais como sombra, naufrago, tartaruga, congelar e descongelar, pega-pega, bem como práticas esportivas diversas. Estes tipos de movimentos corporais adaptados às crianças são capazes de envolver e fazer com que estas comecem a adquirir o hábito de praticar a cultura corporal de maneira regular, sendo isto essencial no âmbito da aula de Educação Física.

Segundo Ferreira et al. (2017) a Educação Física para crianças pode ser estimulada através da utilização de jogo, esportes, danças, ginásticas, exercícios aeróbicos, visando a melhoria da saúde, e também da sensação de bem-estar, promovendo a interação social com os colegas, e a qualidade de vida.

Segundo Silva et al. (2017) o professor de Educação Física contribui na transformação de hábitos e de estilos de vida das crianças. Para tanto precisa levar em consideração o estado nutricional de cada uma, os padrões de comportamento, e as condições culturais e sociais.

Dias et al. (2017) concordam que a atividade é essencial, uma vez que o sobrepeso e a obesidade precisam ser prevenidos desde a infância, tendo em vista que nesta faixa etária as crianças tendem a não ser alimentar de forma saudável, bem como permanecem muito tempo na frente da TV, do celular, do videogame, com elevado nível de imobilidade.

Segundo Peres et al. (2018) o professor de Educação Física precisa estar qualificado para desenvolver uma estratégia voltada para atender as crianças obesas, levando em conta a necessidade de educação na promoção do estilo de vida saudável e práticas regulares de atividade física. Assim, é preciso transformar a aula de Educação Física em uma prática corporal agradável, ao mesmo tempo em que efetivo em resultados e alcance de objetivos.

Este ponto parece ser consensual na literatura a respeito deste tema, Segundo Paes et al. (2015) o professor de Educação Física não deve apenas incentivar a prática corporal, buscando informar acerca das contribuições para saúde, prevenção da obesidade e sobrepeso de um estilo de vida saudável.

Segundo Paixão et al. (2016) a Educação Física pode contribuir dentro de uma estratégia global de tratamento e prevenção da obesidade, uma vez que além dos problemas de saúde, a obesidade resulta em rejeição ou atitudes preconceituosas entre crianças, pois a criança obesa pode ser vista como menos atraente, preguiçosa ou desleixada quando comparada com outra criança com o peso adequado a sua faixa etária. Isto é resultado do padrão de beleza prevalecente na sociedade.

Oliveira et al. (2017) as aulas de Educação Física podem contribuir para redução da estratégia de prevenção e tratamento da obesidade, mas não pode se encontrar restrita a este objetivo, pois sua finalidade vai além de controlar os excessos de adiposidade corporal dos alunos.

Paixão et al. (2016) concordam com o fato que a aula de Educação Física não deve ter como principal objetivo controlar os excessos de adiposidade corporal entre os educandos, pois este precisa acima de tudo ser uma preocupação da família, da escola, e do poder público. A Educação Física apenas pode contribuir e orientar acerca dos riscos da obesidade, destacando a importância de um estilo de vida saudável. 
Além disto, cabe destacar que Ribeiro et al. (2013) ressaltam que a questão da obesidade na infância está ligada ao funcionamento da família, pois são dos hábitos da criança que geralmente, está vem a desenvolver a obesidade, na grande maioria dos casos. Nesse sentido, não adianta a escola atuar na prevenção desta doença, sem o empenho e inserção da família neste processo.

Isso porque tanto o sedentarismo quanto a alimentação inadequada são os maiores fatores a criança a desenvolver a obesidade e o sobrepeso durante a infância. Assim, de acordo com Younes et al. (2017) só a adoção de uma alimentação saudável, e práticas de atividades físicas regulares que podem tratar e prevenir a obesidade.

Segundo Alves Júnior et al. (2016) a Educação Física pode contribuir de maneira efetiva na melhoria da percepção dos alunos acerca da importância de um estilo de vida saudável e das práticas corporais atualizados, mas sem a inserção da família, este esforço não terá os resultados esperados.

Fonseca Júnior et al. (2013) concorda com isto, e asseguram que a dieta e a prática corporal conjuntamente atuam na redução da gordura corporal, bem como o aumento da massa magra, levando em consideração as comorbidades geradas a partir do excesso de gordura. É isto que deve ser repassado para as famílias, a fim de contribuir no processo de tratamento e prevenção da obesidade na infância.

Wanmacher (2015) concorda sobre a necessidade de inserção da família, e ratifica que para tratar obesidade e sobrepeso é preferencial a ênfase adotada em dieta e atividade física, levando em conta os benefícios do adequado condicionamento físico para a saúde em geral.

Segundo Teixeira et al. (2016) a Educação Física precisa priorizar também o desenvolvimento dos alunos de maneira global, de modo que desenvolva o senso crítico, e não apenas se exercitem, de modo que as aulas sejam pautadas para a importância da saúde.

Paes et al. (2015) concordam com isto, e asseguram que a atividade física é essencial para promover as adaptações positivas na vida da criança, resultando em ganhos de saúde, desenvolvimento motor, e aumento da ativação metabólica.

Segundo Dias et al. (2014) o professor de Educação Física deve desenvolver uma série de atividades aeróbicas de acordo com a faixa etária da criança, os objetivos estabelecidos, dentro de uma metodologia consistente que promova os benefícios em termos de prevenção e tratamento da obesidade.

Rica et al. (2014) concordam que o professor de Educação Física deve adaptar os movimentos corporais de acordo com a faixa etária das crianças. E, acrescentam que as atividades precisam ser potencializadas a fim de adquirir o melhor condicionamento físico possível, pois só assim é possível colaborar com a prevenção e o tratamento do sobrepeso e obesidade, sendo este ponto consensual na literatura.

Somando-se a estes fatores, a prática de atividades físicas contribui para elevar a autoestima, melhorando também o processo de interação social da criança, bem como promovendo o aumento das relações psicossociais, uma vez que ajuda na melhoria da atenção e da memória de curto prazo, que são essenciais no cotidiano, e podem ser estimuladas por meio de práticas corporais devidamente planejadas na aula de educação física.

Segundo Ribeiro et al. (2016) atividade física não contribui apenas para prevenção do sobrepeso e 
obesidade, mas também influencia em aspectos psicossociais, pois seus efeitos vão além dos aspectos físicos, e isto precisa está presente nas dinâmicas e atividades da aula de educação física.

Manfre et al. (2016) concordam sobre os efeitos psicossociais da Educação Física, uma vez que a aula de educação física é essencial não apenas para reduzir a obesidade e o sobrepeso, mas também para o desenvolvimento motor da criança, estimula a participação futura em atividades físicas regulares, auxilia no crescimento, e contribui na melhoria da sensação de bem-estar e qualidade de vida.

Nesse sentido, a aula de Educação Física na infância contribui para que a criança constitua o hábito de praticar atividades físicas, alimentação saudável, se excesso de peso, pois uma vida ativa fisicamente é essencial para prevenção de diversas doenças, bem como para qualidade de vida. E, nessa perspectiva, precisa atrair o aluno obeso, que geralmente sofre pelos fatores psicológicos relativos à autoimagem, e a disseminação na sociedade de um determinando padrão estético como o ideal. Assim, a atividade precisa ser atrativa, instrutiva, espontânea, despertando o interesse dos que possuem sobrepeso, pois aumenta a probabilidade deles começarem a praticar regularmente atividades físicas.

A Educação Física na escola deve também desenvolver uma estratégia para conscientizar as crianças acerca da necessidade de se manter vida ativa, tendo em vista os benefícios para saúde, para interação social, minimizando os efeitos do sedentarismo, e os riscos de desenvolvimento de doenças.

Segundo Teixeira et al. (2016) a aula de Educação Física não se restringe apenas ao desenvolvimento de habilidades motoras, mas também as práticas esportivas, uma vez que o professor tem um amplo material e elementos a considerar e escolher em conformidade com as especificidades da faixa etária das crianças, bem como dos objetivos que deseja alcançar. Assim, jogos, esportes, danças, ginástica, aeróbica podem ser escolhidos dentro do que se deseja alcançar, atuando no sentido de criar um nexo entre o eixo temático proposto e a realidade do aluno.

Nesse contexto, Oliveira et al. (2017) concordam acerca da não restrição da aula de Educação Física, e destacam no que se refere à obesidade infantil, as aulas de educação física podem também refletir as questões sociais e de saúde relativas a esta doença, podendo ser desenvolvimento com professores de outras disciplinas atividades conjuntas. Como exemplo, uma aula de ciências sobre os efeitos do excesso de peso.

As atividades na aula de Educação Física também podem ser divididas conforme as especificidades de cada um. Atividades vigorosas geralmente são negativamente recebidas entre os que mantêm excesso de peso. Assim, as atividades precisam ser delineadas dentro dos diversos parâmetros e características de cada grupo, pois estas precisam atingir os objetivos a que se destinam.

A Educação Física como parte da estratégia de intervenção global na obesidade e sobrepeso, é de se reconhecer que está não resolve, pois, e preciso uma mudança de estilo de vida, acompanhamento multidisciplinar, inserção da família neste processo, e alinhar alimentação adequada com prática regular assistida por profissional de educação física de maneira regular.

As aulas de Educação Física escolar contribuem de maneira promissora para prevenção e tratamento da obesidade, e promovem a importância da prática regular de atividade física e da alimentação adequada. Isso ocorre porque o uso de diversos movimentos corporais e técnicas, dentro de uma estratégia 
de educação física, é responsável por desenvolver estruturas motoras, sociais e cognitivas nas crianças, estimulando a criança a realizar atividades físicas, se movimentar, o que contribui para redução dos riscos de sobrepeso e obesidade.

\section{CONCLUSÕES}

Durante esta pesquisa foi possível identificar que as contribuições da Educação Física para prevenção e tratamento da obesidade são bastante efetivas, e dizem respeito a: atividades variadas que tornam a prática da Educação Física em algo agradável e com resultados efetivos; ajuda no processo de formação da prática regular de atividade físicas; conscientização acerca da necessidade de uma alimentação saudável aliada a práticas corporais; incentivo para mudança do estilo de vida sedentário para um ativo; conscientização acerca dos malefícios da obesidade e sobrepeso e comorbidades; inserção da família no processo de prevenção e tratamento da obesidade.

A obesidade durante a infância faz mal tanto em termos de saúde, pois deixa a criança suscetível a desenvolver outras doenças, e também na vida adulta, quanto também traz prejuízos ao processo de interação social, e problemas psicossociais, isto requer tratamento precoce e prevenção efetiva, podendo a aula de Educação Física contribuir dentro de um tratamento global, pois não se pode esperar que a aula de Educação Física fosse à terapêutica exclusiva usada contra obesidade.

A obesidade afeta a rotina, o desenvolvimento motor da criança, atrapalha a estima, o sentimento de bem-estar, deixando-a suscetível a uma série de problemas de saúde. Assim, é preciso que seja tratada por profissionais de saúde, mude os hábitos, e tenha uma vida com alimentação saudável, prática adequada de atividade assistida por um profissional de Educação Física, com envolvimento total da família para incentivar e ajudar na mudança de estilo de vida.

Para tanto, surge a necessidade de disseminação acerca do conhecimento a respeito da obesidade e de suas consequências para as crianças, de modo que as causas sejam evitadas e, em caso de ocorrência, haja tratamento adequado, precoce com intervenções efetivas, e as contribuições da aula de Educação Física, pois a escola também deve colaborar para prevenção e tratamento da obesidade infantil.

\section{REFERÊNCIAS}

ALMEIDA, M. E. F.; RAMOS, J. A. S. C.; GALVÃO, B. F. R. C.; SILVA, A. H.; MOREIRA, M. M.; TAVARES, R. O.; SANTOS, V. S.. Efeito das práticas extensionistas de reeducação alimentar e atividade física no peso corporal de crianças. Interfaces: Revista de Extensão da UFMG, v.4, n.1, p.48-62, 2016.

ALVES JUNIOR, T. A.; JUNIOR, F. J. A.; SILVA, C. S.; SOUSA, L. A.; CARVALHO, A. B. L.; ANTONIO, B.; FIGUEREDO, S.; IVNA, Z.; PONTES JÚNIOR, J.. Auto- percepção do papel do profissional de educação física no combate à obesidade: um estudo piloto. Motricidade, v.12, n.1, p.30-41, 2016.

BARBOSA, J. P. A. S.; BASSO, L.; BARTHOLOMEU, T.; PRISTA, A.; REZENDE, J. A. S.; OLIVEIRA, J. A.; TANI, G. O.; MAIA, J. A. R.; FORJAZ, C. L. M.. Relação entre atividade física, aptidão física e risco cardiovascular: estudo em Muzambinho, Minas Gerais. Rev. Bras. Med. Esporte, v.24, n.1, p.73-77, 2018.

BRAVIN, M. B.; ROSA, A. R.; PARREIRA, M. B.; PRADO, A. F.. A influência do exercício físico na obesidade infantil. Revista Ciência e Estudos Acadêmicos de Medicina, v.1, n.4, p.3751, 2015.

CERRONE, A. L.; TEIXEIRA, C. V. L. S.; REBELO, R. A.; CARANTI, D. A.; GOMES, R. J.. Diabetes Mellitus tipo 3 e exercício físico: relações entre obesidade, resistência insulínica e distúrbios cognitivos. Revista Brasileira de Obesidade, Nutrição e Emagrecimento, São Paulo, v.12, n.71. p.336345, 2018. 
DIAS, P. C.; HENRIQUES, P.; ANJOS, L. A.; BURLANDY, L. Obesidade e políticas públicas: concepções e estratégias adotadas pelo governo brasileiro. Cad. Saúde Pública, v.33, n.7, p.1-11, 2017.

DIAS, I. B. F.; MONTENEGRO, R. A.; MONTEIRO, W. D. Exercícios físicos como estratégia de prevenção e tratamento da obesidade: aspectos fisiológicos e metodológicos. Revista HUPE, Rio de Janeiro, v.13, n.1, p.7079, 2014.

ESMERALDO, R. S.; SILVA, A. O.; LIMA, F. D.; SILVA, V. V.; DANTAS, R. A. E.; OLIVEIRA, R. J.; SOUZA, H. A.; MOTA, M. R.. Prevenção da obesidade de forma multidisciplinar no contexto escolar. Universitas: Ciências da Saúde, Brasília, v.12, n.1, p.59-67, 2014

FERREIRA, J. B.; CARVALHO, M. S.; SOUZA, F. T. R.. Contribuição da atividade física na prevenção da obesidade em alunos do $4^{\circ}$ ao $5^{\circ}$ ano. Revista Olhar Científico, v.03, n.1, p.428-444, 2017.

FONSECA JÚNIOR, S. J.; SÁ, C. G. A. B.; RODRIGUES, P. A. F.; OLIVEIRA, A. J.; FERNANDES FILHO, J.. Exercício físico e obesidade mórbida: uma revisão sistemática. Arq. Bras. Cir. Dig., v.26, n.1, p.67-73, 2013.

LOURENÇO, B. S.; PERES, M. A. A.; PORTO, I. S.; OLIVEIRA, R M. P.; DUTRA, V. F. D.. Atividade física como uma estratégia terapêutica em saúde mental: revisão integrativa com implicação para o cuidado de enfermagem. Esc. Anna Nery; vol.21, n.3, p.1-8, 2017.

MANFRE, S. D. M.; SELOW, M. L. C.. A influência da educação física no combate à obesidade infantil. Vitrine Prod. Acad. Curitiba, v.4, n.1, p.300-458, 2016.

OLIVEIRA, L. C.; FERRARI, G. L. M.; ARAÚJO, T. L.; MATSUDO, V.. Excesso de peso, obesidade, passos e atividade física de moderada a vigorosa em crianças. Rev. Saúde Pública; vol.51, n.38, p.1-12, 2017

PAES, S. T.; MARINS, J. C. B.; ANDREAZZI, A. E.. Efeitos metabólicos do exercício físico na obesidade infantil: uma visão atual. Rev. Paul Pediatr., v.33, n.1, p.122-129, 2015.

PAIXÃO, J. A.; AGUIAR, C. M.; SILVEIRA, F. S. A.. Percepção da obesidade juvenil entre professores de educação física na educação básica. Rev. Bras. Med. Esporte, v.22, n.6, p.501505, 2016

PERES, C. V.; LARA, S.; COPETTI, J.; LANES, K. G.; SOARES, M. C.. Percepção de Estudantes Sobre Saúde, Alimentação e Atividade Física Após Intervenção com a Metodologia da
Problematização. Contexto \& Educação, v.33, n.104, p.346364, 2018.

PIMENTA, T. A. M.; PEREIRA, I. M. D.. As contribuições da intervenção multiprofissional na obesidade infantil no contexto de violência urbana. Publ. UEPG Ci. Soc. Apl., Ponta Grossa, v.22, n.1, p.53-63, 2014

RIBEIRO, A. J. P.; FACHINETO, S.; PEDROZO, S. C.; TRENTIN, A. P.; ZAPOANI, C.. Prevalência de sobrepeso e obesidade em escolares com idade de 7 a 17 anos, residentes nos municípios pertencentes à secretaria de desenvolvimento regional de São Miguel do Oeste/SC. Conexões: Revista da Faculdade de Educação Física da UNICAMP, Campinas, v.11, n.1, p.57-73, 2013.

RIBEIRO, L. S.; TRIANI, F. S.. A obesidade na infância e o protagonismo da educação física escolar. Caderno de Educação Física e Esporte, Marechal Cândido Rondon, v.14, n.1, p.79-88, 2016

RICA, R. L.; MIRANDA, M. L. J.; EVANGELISTA, A. L.; POLITO, L. F. T.; SERRA, A. J.; FIGUEIRA JUNIOR, A.; GAMA, E. F.; ALONSO, A. C.; BOCALINI, D. S.. Contribuições da atividade física no tratamento de idosos com transtorno depressivo: uma breve revisão. Revista Corpo Consciência, Santo André, v.19, n.2, p.21-33, 2014

SILVA, F. A. L.; BEZERRA, J. A. X.. Benefícios da atividade física no controle da obesidade infantil. Revista Campos do Saber, v.3, n.1, p.201-218, 2017

SOUZA, G. E. S.; PRUDENCIATTO, M. R.; TANAKA, R. S.; MARTELLI, A.; DELBIM, L. R.. Exercícios físicos como ferramenta de enfrentamento às comorbidades associadas à obesidade: revisão de literatura. Arch. Health Invest., v.5, n.2, p.112-119, 2016.

TEIXEIRA, R. C.; COSTA, S. P.; OLIVEIRA, G. V.; CANDIDO, F. N.; RAFAEL, L. M.; MAZINI FILHO, M. L. M.. Influências da mídia e das relações sociais na obesidade de escolares e a educação física como ferramenta de prevenção. Cinergis, Santa Cruz do Sul, v.17, n.2, p.1-6, 2016

WANNMACHER, L.. Obesidade como fator de risco para morbidade e mortalidade: evidências sobre o manejo com medidas não medicamentosas. OPAS/OMS: Representação Brasil, v.1, n.7, p.1-10, 2015.

YOUNES, S.; FRIZON, M. L. R.; LUCIA, M.; ARAÚJO, F.; CEZAR, A.. Itinerário terapêutico de pacientes com obesidade atendidos em serviço de alta complexidade de um hospital universitário. Saúde em Debate, v.41, n.115, p.1046-1060, 2017.

A CBPC - Companhia Brasileira de Produção Científica (CNPJ: 11.221.422/0001-03) detém os direitos materiais desta publicação. Os direitos referem-se à publicação do trabalho em qualquer parte do mundo, incluindo os direitos às renovações, expansões e disseminações da contribuição, bem como outros direitos subsidiários. Todos os trabalhos publicados eletronicamente poderão posteriormente ser publicados em coletâneas impressas sob coordenação da Sustenere Publishing, da Companhia Brasileira de Produção Científica e seus parceiros autorizados. Os (as) autores (as) preservam os direitos autorais, mas não têm permissão para a publicação da contribuição em outro meio, impresso ou digital, em português ou em tradução. 